9 - ORIGINAL ARTICLE

EXPERIMENTAL UROLOGY

\title{
Quantitative analysis of the renal aging in rats. Stereological study ${ }^{1}$
}

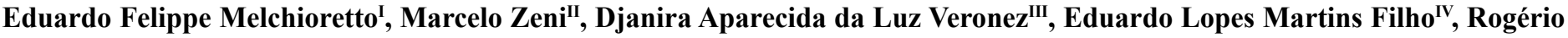 \\ de Fraga $^{v}$
}

DOI: http://dx.doi.org/10.1590/S0102-865020160050000009

IFellow Master degree, Postgraduate Program in Surgical Clinic, Department of Urology, Federal University of Parana (UFPR), Curitiba-PR, Brazil. Scientific, intellectual, conception and design of the study; acquisition, analysis and interpretation of data; technical procedures; histopathological examinations; statitics analysis; manuscript writing; critical revision.

${ }^{I} \mathrm{MD}$, Volunteer, Department of Urology, UFPR, Curitiba-PR, Brazil. Scientific and intellectual content of the study, acquisition of data, technical procedures.

IIIPhD, Associate Professor, Department of Anatomy, School of Medicine, UFPR, Curitiba-PR, Brazil. Scientific, intellectual, conception and design of the study; analysis and interpretation of data; histopathological examinations; critical revision.

${ }^{\mathrm{IV}}$ Graduate student, School of Medicine, UFPR, Curitiba-PR, Brazil. Acquisition of data, technical procedures, histopathological examinations.

${ }^{\mathrm{v}} \mathrm{PhD}$, Associate Professor, Department of Urology, School of Medicine, UFPR, Curitiba-PR, Brazil. Scientific, intellectual, conception and design of the study; analysis and interpretation of data; statistics analysis; critical revision.

\begin{abstract}
PURPOSE: To evaluate the renal function and the renal histological alterations through the stereology and morphometrics in rats submitted to the natural process of aging.

METHODS: Seventy two Wistar rats, divided in six groups. Each group was sacrificed in a different age: 3, 6, 9, 12, 18 and 24 months. It was performed right nephrectomy, stereological and morphometric analysis of the renal tissue (renal volume and weight, density of volume $\left(\mathrm{Vv}_{\text {[glom }}\right)$ and numerical density $\left(\mathrm{Nv}_{\text {[glom] }}\right)$ of the renal glomeruli and average glomerular volume $\left(\mathrm{Vol}_{\text {[glom] }}\right)$ and also it was evaluated the renal function for the dosage of serum creatinine and urea.

RESULTS: There was significant decrease of the renal function in the oldest rats. The renal volume presented gradual increase during the development of the rats with the biggest values registered in the group of animals at 12 months of age and significant progressive decrease in older animals. $\mathrm{Vv}_{\text {[glom] }}$ presented statistically significant gradual reduction between the groups and the $\mathrm{Nv}_{\text {[glom] }}$ also decreased significantly.

CONCLUSIONS: The renal function proved to be inferior in senile rats when compared to the young rats. The morphometric and stereological analysis evidenced renal atrophy, gradual reduction of the volume density and numerical density of the renal glomeruli associated to the aging process.
\end{abstract}

Key words: Aging. Kidney. Histology. Rats. 


\section{Introduction}

The aging process is inevitable and culminates in the functional worsening of multiple systems, increase of the morbidity and mortality ${ }^{1}$. The effects of the aging in the kidneys are related to the presence of sclerosis in progression, associated to the reduction of the number of functioning nephrons, resulting in the reduction of the renal blood flow and the glomerular filtration ${ }^{2}$.

The pathogenesis of the structural renal changes associated to the aging is not yet completely known. Genetic and hemodynamic factors had been associated with the progression of the morphologic alterations related to age and these structural alterations of the renal aging are also very unspecific, found in many conditions, including diabetes, hypertension and arteriosclerosis ${ }^{3}$.

The accuracy for determination of structural alterations of the agencies is extended with the use of the stereology, which is a method that uses systematic, uniform and random samples to supply quantitative data with minimum bias ${ }^{4}$.

There are few studies using stereology to evaluate the renal structural alterations secondary to the aging process, therefore this work aims to evaluate the renal histological alterations through the stereology and morphometrics; and the renal function, through the examination of the serum urea and creatinine in rats submitted to the natural process of aging.

\section{Methods}

All the ethical principles in the animal testing established by the Brazilian College of Animal Experimentation (COBEA) had been observed and also the requirements established in the "Guide for the Care and Use of Experimental Animals" had been respected, being the experiment approved by the local committee of ethics.

For the study, 72 male albino Wistar rats (Rattus novergicus albinus, Rodentia, Mammalia) had been kept in an environment with controlled temperature in 22 degrees Celsius, light/dark cycle of 12 hours, controlled humidity of the air and free of external noises. They had all received purified water and $\mathrm{ad}$ libitum feeding with specific food for the species during the period of the experiment.

The animals were divided in six groups of 12 animals each and were sacrificed at different ages: group 1, at 3 months of age; group 2, at 6 months of age; group 3, at 9 months of age; group 4, at 12 months of age; group 5, at 18 months of age; and group 6, at 24 months of age.
In the experimentation room, the weighing in an ultrasensitive calibrated scale and measurement of the stature of the animal were made.

For the procedure, the animals were submitted to anesthesia with a solution of Ketamine hydrochloride $(57.67 \mathrm{mg} /$ $\mathrm{mL}$ ) associated $2 \%$ of Xylazine hydrochloride $(2 \mathrm{~g})$, with application of $1 \mathrm{ml} / 1000$ grams of live weight, via intraperitoneal injection under aseptic conditions. The procedure consisted in the performance of laparotomy and median thoracotomy and subsequent intracardiac puncture for blood collection and induction of cardiorespiratory arrest by exsanguination.

Next, the experiment proceeded with the kidneys dissection performed bilaterally, tie of the renal vases and ureters and conduct of bilateral nephrectomy. The left kidney was immediately frozen under the temperature of $-80^{\circ} \mathrm{C}$ (to be used in another study) and the right kidney was submitted the weighing in electronic scale of high precision and its dimensions (length, width and thickness) were measured with a digital caliper.

Also the following organs were dried up to be used in other studies on the aging process: testicles, bladder, corpus cavernosum and urethra, aorta, heart, liver and brain.

\section{Biochemical analysis}

The collected blood samples from the animals were sent to the laboratory of biochemical analyses and a measurement of serum creatinine and urea though the enzymatic colorimetric method was performed, being the measurement unit $\mathrm{mg} / \mathrm{dL}^{5}$.

\section{Morphological, morphometric and stereological analysis}

The renal volume (V) was calculated from the linear measurement, using the formula for the volume of an ellipsoid recommended by Barr (1990): Volume (V) = Length (C) x Width (L) $x$ Thickness (E) x $0.523^{6}$.

After the verification of the measures of weight, length, width and thickness, the right kidney was bipartite longitudinally and set in ALFAC (85 parts of ethyl alcohol 80\%, 10 parts of formaldehyde $40 \%$ and 5 parts of glacial ascetic acid, made at the moment of use) for 16 hours. The material then was dehydrated in a decreasing series of xylol and alcohols, for posterior inclusion in paraffin blocks.

After that, the kidneys were submitted to the successive cuts in microtome with $7 \mu \mathrm{m}$ of thickness (American Optical, 
Spencer AO 820). Since the kidney is an anisotropic organ (the glomeruli are located predominantly in the cortical region) the Orientator Method was used to obtain random and uniformly isotropic cuts (cuts AUI).

The physical Disector method ${ }^{8}$ was used to calculate the numerical density of the glomeruli $\left(\mathrm{Nv}_{\text {[glom] }}\right)$. The sampling of the renal tissue was carried through with two consecutive cuts; chosen 1 every 5 cuts - presenting a thickness of 35 micrometers between the plans - for the determination of the three-dimensional quantitative parameters of the renal glomeruli from bi-dimensional cuts.

Later, the histological blades were mounted with 5 cuts of each renal unit for the execution of the histochemical method Hematoxylin and Eosin stain (HE).

The analysis of the blades submitted to the HE stain was made in biological trinocular microscope with plain objective Bel Photonics lens, model BIO2 Polaris (Bel Photonics do Brasil Ltda., São Paulo, Brazil) with image capture system BIOCAM CMOS SERIES 3.0 ${ }^{\circledR}$ and software Home Mirage $I^{\circledR}$ connected. After that, the captured images were used for the analysis of the stereological parameters for attainment of the volumetric density $\left(\mathrm{Vv}_{[\text {glom }]}\right)$, numerical density $\left(\mathrm{Nv}_{\text {[glom] }}\right)$ and average volume $\left(\mathrm{Vol}_{\text {[glom] }}\right)$ of the renal glomeruli.

To determine the three-dimension of the kidney the stereological method $M_{42}$ system-test was used. This was superimposed on the histological images in order to count the of points and intersections test, as described by Mandarim De Lacerda? .

For attainment of the density of volume of the renal glomeruli $\left(\mathrm{Vv}_{\text {[glom] }}\right)$ the following calculation was carried through: $\mathbf{V} \mathbf{v}_{\text {[glom] }}=\mathbf{P}_{\text {[glom] }} / \mathbf{P}_{\mathrm{T}}\left(\mu \mathbf{m}^{0}\right)$

$\mathrm{P}$ [glom] being the number of points that cross renal glomeruli and $\mathrm{P}_{\mathrm{T}}$ the number of points-test. The values of the volumetric density were multiplied by 100 for expression of the results in percentage.

The numerical density of the renal glomeruli $\left(\mathrm{Nv}_{\text {[glom] }}\right)$ was calculated through the formulas:

$$
\begin{aligned}
& \text { Vol[disector] }=\mathbf{e} \cdot \mathbf{A}_{\mathrm{T}} \\
& \mathbf{N v}_{\text {[glom] }}=\boldsymbol{\Sigma} \mathbf{Q}_{\text {A[glom] }} / \text { Vol[disector] }\left(\mathbf{1} / \mathbf{m m}^{\mathbf{3}}\right) \\
& \text { Being: } \\
& \mathrm{e}=\text { thickness of the micrometer } \\
& \mathrm{A}_{\mathrm{T}}=\text { area-test of the superior plan } \\
& \Sigma \mathrm{Q}_{\text {A[glom] }}=\text { sum of the number of renal glomeruli }
\end{aligned}
$$

To obtain the average volume of the renal glomeruli $\left(\mathrm{Vol}_{\text {[glom] }}\right)$, the division between the volumetric density $\left(\mathrm{Vv}_{\text {[glom] }}\right)$ and the numerical density of the renal glomeruli $\left(\mathrm{Nv}_{\text {[glom] }}\right)$ was made. The result was expressed in cubic micrometers $\left(\mu \mathrm{m}^{3}\right)$.

\section{Statistical analysis}

The results obtained in the experiment were described by averages, medium, minimum values, maximum values and standards deviations. For the comparison of the groups in relation to the quantitative variables that had taken care of the normality condition, the model of analysis of the variance (ANOVA) with a factor was considered. The LSD test (least significant difference) was used for the comparisons of groups two by two. In the average glomerular volume, the comparison of the groups was made using the non-parametric test Kruskal-Wallis one-way analysis of variance. Values of $\mathrm{p} \leq 0.05$ had indicated statistical significance. For each one of the variables, the null hypothesis of the averages being equal in all the groups, versus the alternative hypothesis of at least one of the groups having a different average from the others was tested. In case of rejection of the null hypothesis, the groups were compared two by two. The data were analyzed with computer program IBM SPSS Statistics v.20.0.

\section{Results}

No loss occurred during the study, as in the last group all the 12 animals at 24 months of age were alive. The animals with the longer survival showed evident signs of aging, such as thinning hair and hypoactivity. With regards to the length and weight, the animals had had a statistically significant gradual increase until the group at 12 months of life, followed by discrete reduction in the rats of the last groups (Figure 1). 

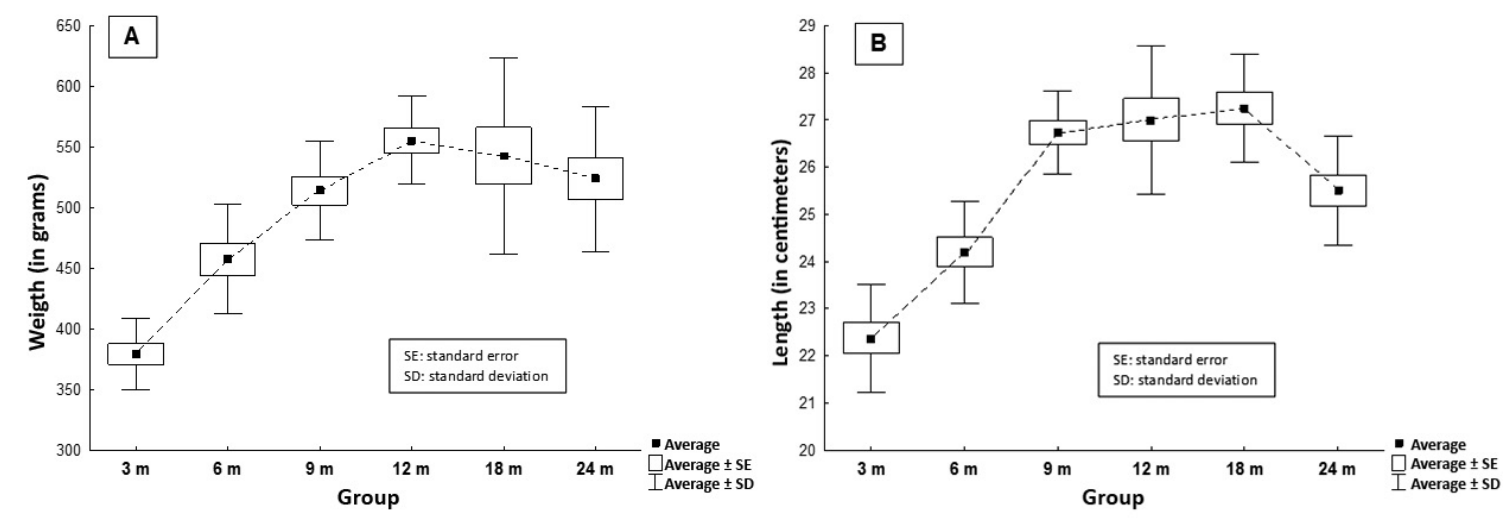

FIGURE 1 - A) Graph of the evolution of the weight (in grams) of the animals in the groups. B) Evolution of the length of the animals (in centimeters) in the different groups.

\section{Biochemical analysis}

The statistical analysis of the values of the serum creatinine had shown gradual increase over time, presenting significant statistical difference $(\mathrm{p} \leq 0.05)$ in the comparison of the animals of the groups of young rats (group at 3 and 6 months of age - average creatinine $0.53 \pm 0.16 \mathrm{mg} / \mathrm{dL}$ and $0.56 \pm 0.09 \mathrm{mg} / \mathrm{dL}$, respectively) when compared with the animals of the groups of

rats at more advanced age (12, 18 and 24 months of age - average creatinine $0.74 \pm 0.21 \mathrm{mg} / \mathrm{dL}, 0.77 \pm 0.17 \mathrm{mg} / \mathrm{dL}$ and $0.90 \pm 0.33$ $\mathrm{mg} / \mathrm{dL}$, respectively). In the comparison between the animals of the groups at more than 12 months of age there was no significant difference in the values of the serum creatinine (Figure 2A). The values of the measurement of the serum urea had not shown statistical difference between the groups $(\mathrm{p}=0.557)$ (Figure $2 \mathrm{~B})$.
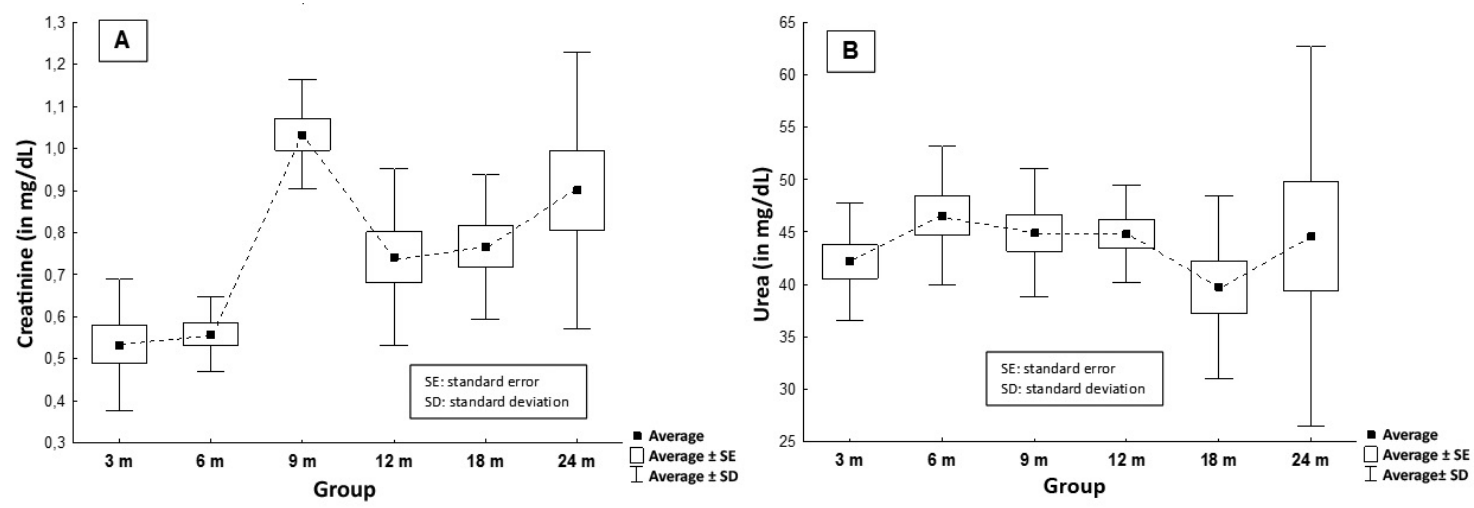

FIGURE 2 - Result of the serum creatinine (A) and urea (B) of the animals in the different groups.

\section{Renal morphometric analysis}

The examination of the renal weight presented statistically lower values in the group of animals at 3 months of age (average of $1.28 \pm 0.13 \mathrm{~g}$ ) in comparison to the other groups (except group at 9 months of age) (Figure $3 \mathrm{~A}$ ).

The renal volume measured presented statistically significant increase between the group at 3 months of age (average of $433.8 \pm 74.58 \mathrm{~mm}^{3}$ ) and the group at 6 months of age (average of $\left.1124.6 \pm 82.5 \mathrm{~mm}^{3}\right)(\mathrm{p}<0.001)$. A significant increase of the renal volume was also evidenced between the animals of the group at 6 months of age and the group of animals at 12 months of age (average of $\left.1267.2 \pm 124.0 \mathrm{~mm}^{3}\right)(\mathrm{p}=0.028)$. After a peak with the group at 12 months of age, a gradual reduction of the renal volume occurred, being that the comparison between the groups at 12 and 18 months of age (average of $579.1 \pm 137.9 \mathrm{~mm}^{3}$ ) was also statistically significant $(\mathrm{p}<0.001)$ (Figure 3B). 

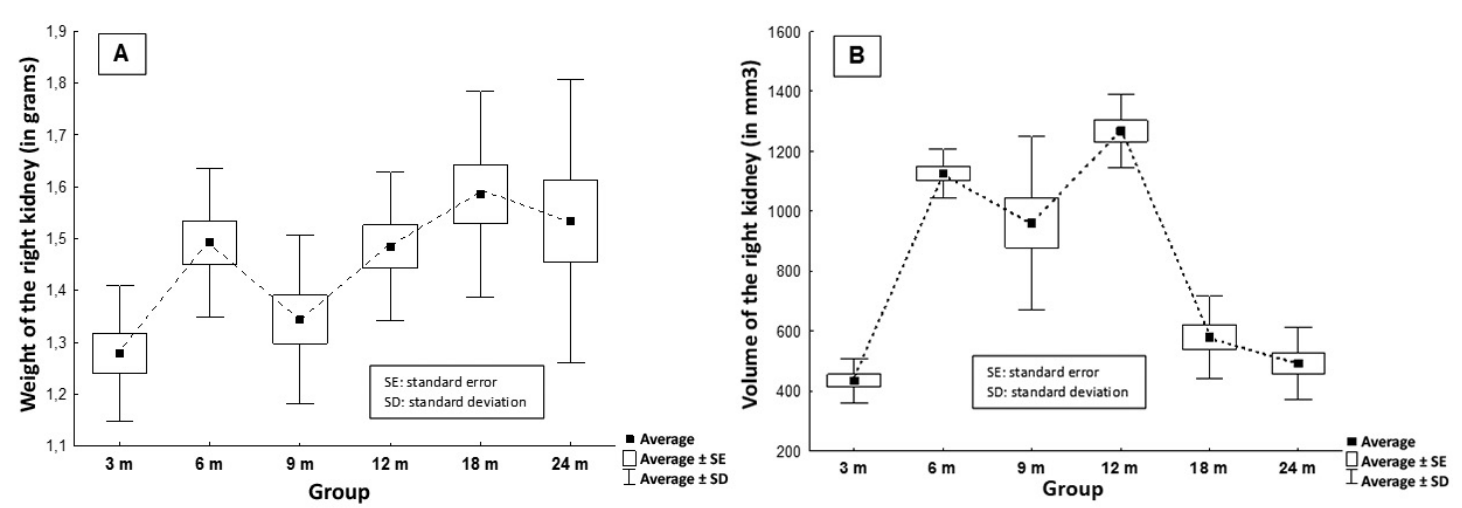

FIGURE 3 - A) Graphic of the evolution of the weight of the right kidney (in grams) in the different groups. B) Graph of the evolution of the volume of the right kidney (in $\mathrm{mm}^{3}$ ) in the different groups.

\section{Stereological analysis}

The quantitative examination of the glomerular volume density $\left(\mathrm{Vv}_{\text {[glom] }}\right)$ showed statistically significant gradual reduction between the groups (Figure 4).

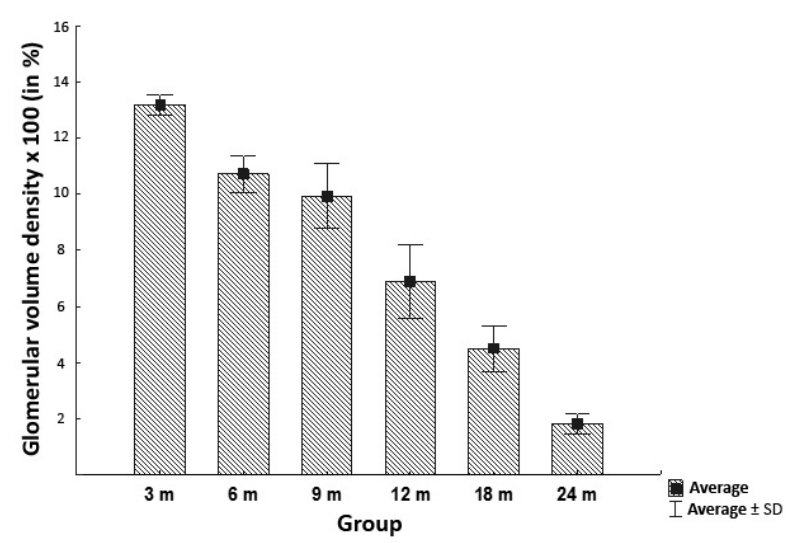

FIGURE 4 - Values of the glomerular volume density $\left(\mathrm{Vv}_{\text {[glom] }}\right)$ in the groups.

The glomerular numerical density $\left(\mathrm{Nv}_{\text {[glom] }}\right)$ surveyed demonstrated statistically significant reduction between the groups of rats at 3 months of age (average of $165.77 \pm 3.13$ glomeruli per $\mathrm{mm}^{3}$ ) and 6 months of age (average of $135.32 \pm 12.89$ glomeruli per $\left.\mathrm{mm}^{3}\right)(\mathrm{p}<0.001)$. An increase in the numerical density in the rats at 9 months of age (average of $148.71 \pm 15.78$ glomeruli per $\mathrm{mm}^{3}$ ) in relation to the group at 6 months of age was evidenced $(\mathrm{p}=0.007)$. The glomerular numerical density in the groups over 9 months of age came back to present gradual reduction until reaching an average of $26.42 \pm 5.07$ glomeruli per $\mathrm{mm}^{3}$ in the group of rats at 24 months of age. This gradual reduction presented great statistical relevance $(\mathrm{p}<0.001)$ (Figures 5 and 6).

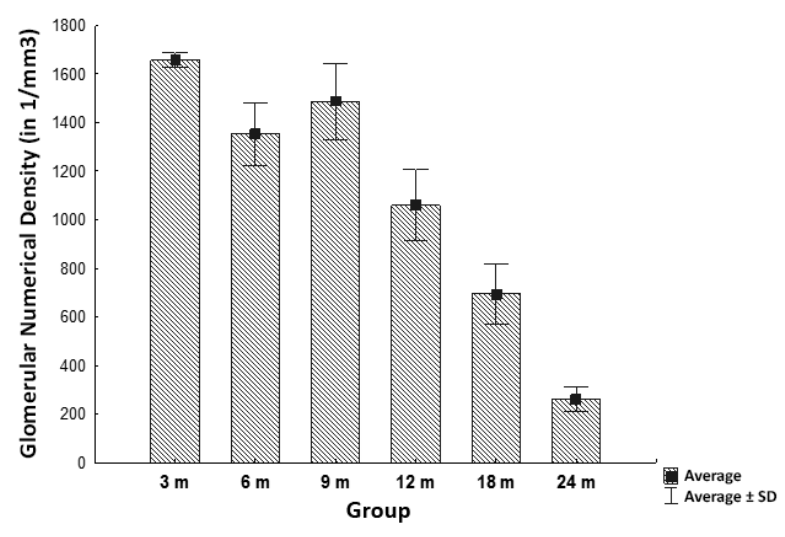

FIGURE 5 - Values of the glomerular numerical density $\left(\mathrm{Nv}_{\text {[glom] }}\right)$ in the groups (values in $1 / \mathrm{mm}^{3}$ )
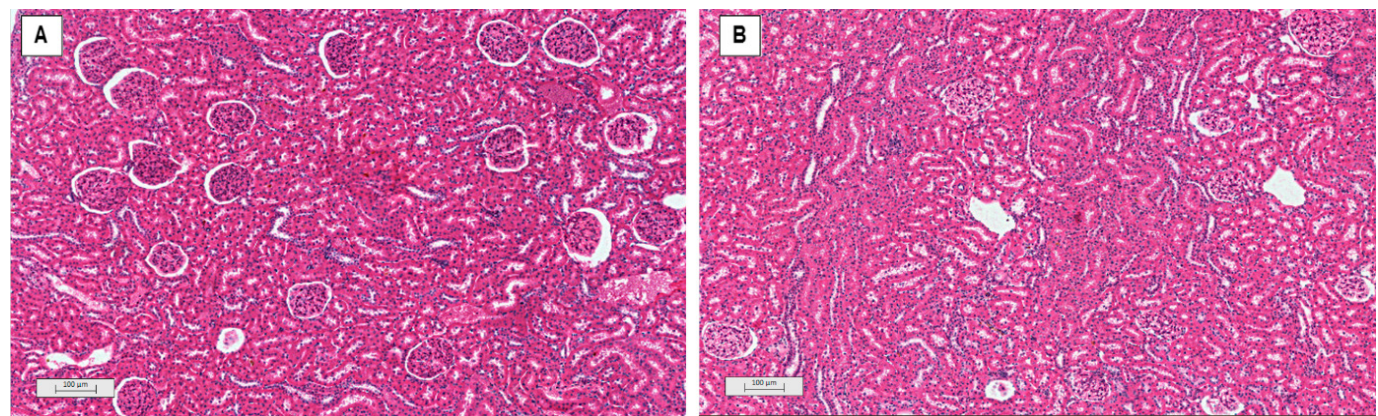

FIGURE 6 - Photomicrograph of the kidney cortex using Hematoxylin-Eosin. Magnification: x40. Marked difference between the number of identified glomeruli (arrows) in the 3-month group (A) versus 24-months group (B). 
The mean glomerular volume did not present statistical difference between the groups of rats with 3 and 6 months of age $(p=0.792)$. Between the groups of animals at 6 months of age and the remaining with rats at more advanced age, a statistically significant reduction $(\mathrm{p}<0.001)$ of the mean glomerular volume occurred. Between the animals older than 9 months, the mean glomerular volume did not present significant alterations (Table 1).

TABLE 1 - Values of the mean glomerular volume ( $\mathrm{Vol}_{[}$ ) in the groups (values in $\mu \mathrm{m}^{3}$ ).

\begin{tabular}{|c|c|c|c|c|c|c|c|c|}
\hline Variable & Group & $\mathrm{n}$ & Average & Medium & Minimum & Maximum & Standard deviation & Value of $\mathrm{p}^{*}$ \\
\hline \multirow{6}{*}{$\begin{array}{l}\text { Vol }_{\text {[glom] }} \\
\left(\text { in } \mu \mathrm{m}^{3} \text { ) }\right.\end{array}$} & 3 months & 12 & 7.96 & 7.99 & 7.67 & 8.26 & 0.20 & \\
\hline & 6 months & 12 & 8.00 & 8.03 & 7.19 & 8.58 & 0.40 & \\
\hline & 9 months & 12 & 6.68 & 6.73 & 6.22 & 7.08 & 0.24 & \\
\hline & 12 months & 12 & 6.45 & 6.48 & 5.83 & 7.37 & 0.51 & \\
\hline & 18 months & 12 & 6.56 & 6.66 & 5.37 & 7.26 & 0.54 & \\
\hline & 24 months & 12 & 6.88 & 6.88 & 6.88 & 6.88 & 0.001 & $<0.001$ \\
\hline
\end{tabular}

*ANOVA with a factor, $\mathrm{p} \leq 0.05$

\section{Discussion}

The use of animal models in experimental studies has been widely spread since the beginning of the last century. Even with its reduction in the last two decades due the ethical concerns, it is estimated that about 12 million animals are used per year in researches in the United States ${ }^{10}$.

In aging and longevity research this model becomes fundamental, since it allows to follow the entire cycle of life in a shorter period of time and to control the environment exposition during all the life of the animal.

In the present study, the animals of the last group had reached the end of the follow-up time at 24 months of life, thus, on the basis of its cycle of life, they can be considered elderly rats $^{11}$. The development of the animals based on their weight was considered adequate regarding the standard curves found in literature ${ }^{12}$.

The senescence is associated with a gradual reduction of the glomerular filtration rate. Previous studies on renal aging in rats ${ }^{13,14}$ had demonstrated gradual reduction of the clearance of creatinine overtime in rats at up to 18 months of age, corroborating with our finding of significantly inferior values of the serum creatinine in younger animals (group at 3 and 6 months of age) in comparison to the animals of more advanced age (12, 18 and 24 months of age). Another point to be considered is the fact that endogenous creatinine is produced in the organism to be directly proportional to the muscular mass. In Wistar rats, the decline in the muscular mass is very small (approximately 5\%), whereas in men these values are around $25 \%$ reduction ${ }^{15}$. This reduction of the muscular mass does not necessarily reflects in an expected reduction of the serum levels of creatinine, precisely because of the existence of a reduction of the renal function, as evidenced in the results of our study.

The values of the urea had not presented statistically significant variation between the groups, suggesting that even with the potential reduction of the renal function during the aging process, none of the animals developed accentuated damage capable to install status of advanced renal insufficiency. It is understood however, that the analysis of the concentrations of plasma creatinine and urea is limited and allows only one indirect indication of renal damage, as there are other factors that can be involved in the increase of its serum concentrations.

The histopathological alterations associated to the process of renal aging, such as: atrophy of the organ, reduction of the epithelial cells number of the convoluted tubule, reduction of the number and volumetric reduction of nephrons, arterial alterations, and increase of the number of renal interstice cells and interstitial fibrosis ${ }^{16}$. In our study, the morphmetrics and stereology were used to better determine the renal alterations secondary to the aging process ${ }^{4}$.

The renal weight of the analyzed animals has presented to be compatible with the findings of preliminary studies and was consistent with the physical development of the animals. The renal volume found in the study suggests the same logic, increasing as the animal develops physically - with apex around 12 months of age - and, after that, evolving with gradual reduction demonstrating evident process of atrophy of the organ ${ }^{17}$.

With strong statistical significance, the gradual reduction of the glomerular volume density and the glomerular numerical density found in the stereological analysis of the renal tissue of the rats in the groups of animals gradually older, clearly demonstrates 
the process of renal aging as already well-established in literature $^{17-21}$.

The variation curve of the mean glomerular volume during the aging process evidenced in our work was similar to the ones found in studies lead in human beings ${ }^{19-22}$. However, Cortes et $a l .{ }^{23}$ evidenced a gradual increase on the mean glomerular volume during the aging of Fischer rats. This compensatory glomerular hypertrophy seen in the senile rats is probably due to the reduction of the number of functioning renal glomeruli.

The results of the study strengthen the well appraised information already in literature and can assist in better understanding of the natural process of the aging in rats and stimulate the development of new research on the subject.

\section{Conclusions}

The renal function, evaluated through the serum dosage of creatinine and urea, proved to be inferior in senile rats when compared the young rats. The morphometric and stereological analysis evidenced renal atrophy, gradual reduction of the glomerular volume density and glomerular numerical density associated to the aging process. It was not found significant compensatory glomerular hypertrophy in the senile rats.

\section{References}

1. Hayflick L. How and why we age. Exp Gerontol. 1998 Nov;33(78):639-53. PMID: 9951612.

2. Jassal SV, Oreopoulos, DG. The aging kidney. Geriatr Nephrol Urol. 1998;8(3):141-7. PMID: 10221172.

3. Pannarale G, Carbone R, Del Mastro G, Gallo C, Gattullo V, Natalicchio L, Navarra A, Tedesco A. The aging kidney: structural changes. J Nephrol. 2010 Sep-Oct;23 Suppl 15:S37-40. PMID: 20872369.

4. Bertram JF. Analyzing renal glomeruli with the new stereology. Int Rev Cytol. 1995;161:111-72. PMID: 7558690.

5. Sodré FL, Costa JCB, Lima JCC. Avaliação da função e da lesão renal: um desafio laboratorial. J Bras Patol Med Lab. 2007;43(5):32937. doi: 10.1590/S1676-24442007000500005.

6. Sampaio KMOR, Araújo RB. Ultrasonographic measurement of linear characteristics and renal volumetry in dogs. Arq Bras Med Vet Zootec. 2002;54(3):248-54. doi: 10.1590/S010209352002000300005.

7. Mattfeldt T, Mobius HJ, Mall G. Orthogonal triplet probes: an efficient method for unbiased estimation of lenght and surface of objects unknown orientation in space. J Microsc. 1985;139:279-89. PMID: 3908688.

8. Sterio DC. The unbiased estimation of number and sizes of arbitrary particles using the disector. J Microsc. 1984;134:127-36. PMID: 6737468.

9. Mandarim-de-Lacerda CA. Fisiologia e fisiopatologia: estereologia do rim: determinação do $\mathrm{Vv}, \mathrm{Nv}$ e volume médio do glomérulo. J Bras Nefrol. 2000;22(2):103-9.
10. van Zutphen LF. Use of animals in research: a science - society controversy? The European perspective. ALTEX. 2002;19(3):1404. PMID: 12165817.

11. Quinn R. Comparing rat's to human's age: how old is my rat in people years? Nutrition. 2005;21:775-7. PMID: 15925305.

12. Cossio-Bolaños M, Gómez Campos R, Vargas Vitoria R, Hochmuller Fogaça RT, de Arruda M. Reference curves for assessing the physical growth of male Wistar rats. Nutr Hosp. 2013 Nov 1;28(6):2151-6. PMID: 24506395.

13. Gamba CV, Caraviello AZ, Matsushita A, Alves GM, da Silva LN, Gomes GN, Gil FZ. Effects of dietary lipids on renal function of aged rats. Braz J Med Biol Res. 2001;34(2): 265-69. PMID: 11175504.

14. Fernandez R, Piechnik J, Fabris R, Malnic G, Fernandes LC. Effect of chronic fish oil supplementation on renal function of normal and cachectic rats. Braz J Med Biol Res. 2004;37:1481-9. PMID: 15448868.

15. Ballak SB, Degens H, de Haan A, Jaspers RT. Aging related changes in determinants of muscle force generating capacity: a comparison of muscle aging in men and male rodents. Ageing Res Rev. 2014 Mar;14:43-55. PMID: 24495393.

16. Tauchi H, Tsuboi K, Okutimi J. Age changes in the human kidney of the different races. Gerontologia. 1971;17:87-97. PMID: 5093734.

17. Owen RA, Heywood R. Age-related variations in renal structure and function in Sprague-Dawley rats. Toxicol Pathol. 1986;14(2):15867. PMID: 3764313.

18. Arataki, M. Postnatal growth of kidney with special reference to the number and size of the glomeruli (albino rat). Am J Anat. 1926;36:399-436. doi: 10.1002/aja.1000360302.

19. Newbold KM, Sandison A, Howie AJ. Comparison of size of juxtamedullary and outer cortical glomeruli in normal adult kidney. Virchows Arch A Pathol Anat Histopathol. 1992;420(2): 127-9. PMID: 1549901

20. Silva FG. The aging kidney: a review - part I. Int Urol Nephrol. 2005;37:185-205. PMID: 16132784 .

21. Silva FG. The aging kidney: a review - part II. Int Urol Nephrol. 2005;37:419-32. PMID: 16142578.

22. Goyal VK. Changes with age in the human kidney. Exp Gerontol. 1982;17(5):321-31. PMID: 7169092.

23. Cortes P, Zhao X, Dumier F, Tilley BC, Atherton J. Age-related changes in glomerular volume and hydroxyproline content in rat and human. J Am Soc Nephrol. 1992; 2:1716-25. PMID: 1498277.

\section{Correspondence:}

Eduardo Felippe Melchioretto

Rua Padre Henrique Muller, 219/12

89.280-376 Santa Catarina - RS Brasil

Tel.: (55 47)3633-6863

melchioretto@gmail.com

Received: Jan 12, 2016

Review: Mar 15, 2016

Accepted: Apr 11, 2016

Conflict of interest: none

Financial source: none

${ }^{1}$ Research performed at Laboratory of Anatomy and Experimental Surgery, Division of Urology, Department of Surgery, Federal University of Paraná (UFPR), Curitiba-PR, Brazil. Part of Master degree thesis, Postgraduate Program in Surgical Clinic. Tutor: Rogerio de Fraga. 